Canadian University Music Review

Canadian University Music Review

Revue de musique des universités canadiennes

\title{
Rock Music: Dimensions of a Mass Medium - Meaning Production through Popular Music
}

\section{Peter Wicke}

Volume 10, numéro 2, 1990

Alternative Musicologies

Les Musicologies Alternatives

URI : https://id.erudit.org/iderudit/1014889ar

DOI : https://doi.org/10.7202/1014889ar

Aller au sommaire du numéro

Éditeur(s)

Canadian University Music Society / Société de musique des universités

canadiennes

ISSN

0710-0353 (imprimé)

2291-2436 (numérique)

Découvrir la revue

Citer cet article

Wicke, P. (1990). Rock Music: Dimensions of a Mass Medium — Meaning Production through Popular Music. Canadian University Music Review / Revue de musique des universités canadiennes, 10(2), 137-156.

https://doi.org/10.7202/1014889ar

All Rights Reserved (C Canadian University Music Society / Société de musique des universités canadiennes, 1990
Ce document est protégé par la loi sur le droit d'auteur. L'utilisation des services d'Érudit (y compris la reproduction) est assujettie à sa politique d'utilisation que vous pouvez consulter en ligne.

https://apropos.erudit.org/fr/usagers/politique-dutilisation/ 


\title{
ROCK MUSIC: DIMENSIONS OF A MASS MEDIUM - MEANING PRODUCTION THROUGH POPULAR MUSIC
}

\author{
Peter Wicke
}

\section{THE ROCK SONG AS ART?}

What meaning, significance and value can reside in the musical, gestural and visual materials of a rock song? This question quickly leads into uncharted areas and produces another one: does the high degree of stereotyping to be found in this music allow any kind of differentiated meaning? To be sure, it is always possible to cite examples from the wide variety of this kind of music which apparently testify to the existence of differentiated musical structures and of an aesthetic resulting from contact with other forms of contemporary music (for example, jazz and so-called serious music). But to adopt this strategy bypasses the problem because standardisation of musical structures is endemic in mass-mediated popular musics, not least as a result of new technological processes such as sampling and sequencing. The mere listing of the constituent materials of popular songs reveals that their social, cultural, emotional, affective and ideological references are not solely realised through musical materials, but through a great variety of other materials which, on closer inspection, turn out not to be meaningfully related to one another in such a way as to form a coherent yet complex unity. Not even a reasonably adequate word-sound relationship (to select the dimensions of music and lyrics) can be truly and convincingly demonstrated, because the degree of stereotyping within the stylistic frame of reference of a band or a musician does not allow for the kind of text-related musical differentiations that one would find, for example, in a Schubert song [see, for example, Mellers' (1973) analysis of Beatles' songs]. In addition, there is empirical evidence which throws doubt on the relevance for audiences of the semantictextual relationship in rock and pop songs. As Hirsch has observed:

Teenagers ... tend to be unaware of many song's lyrics and messages; most teenagers are attracted to popular records more by their overall sound and beat - or the performing group - than by their verbal content . . . Systematic social research has yet to demonstrate any effects of popular song lyrics upon their listeners. (Hirsch 1971: 80) 
Key later came to similar conclusions. In a 1975 study he found that not one of the teenage subjects had "any conscious idea what the lyric was about, even though all had heard the song dozens - if not many dozens - of times" (Key 1976: 120).

Rather than being related to the individual songs themselves, the songs' gestural and visual dimensions seem to be connected to modes of performance, to stage-audience relationships, and to the technological requirements and conventions of media such as television, video and film. Evidently, the constituent materials of a song form part of different networks of communication, each with its own codes and conventions. This principle extends even to musical structures themselves. The rhythmic patterns on which musical structures are based follow conventions of movement which flow from the physical activity of dancing. The visualisation of songs in music videos superimposes a further and quite autonomous network of communication invoking pre-existing conventions from cognate forms of audiovisual media such as film which have been synthesized into a distinct code by American Music Television (MTV):

The question must be raised as to whether a mode of creativity based on semantic intentionality forms an appropriate point of departure for the analysis of popular musics which come into being as the result of industrial processes involving a complex division of artistic labour. Quite apart from these processes, songs are inserted into cultural discourses themselves shaped by the images of a musician or band. These images are given expression through print media, interviews, reviews, posters, photographs and radio and television presentations. And behind all this lie sales strategies which attempt to place songs in a context relevant to the personality of a star or, rather, the media construct which is supposed to pass for this personality. These strategies are superimposed on biographical material or on information concerning the alleged or actual "philosophy" of the star and presented as the "expression" of their emotions and experiences. The fact that a song is by the Rolling Stones, Bruce Springsteen, Bob Dylan or Joe Cocker is of no less consequence than the song's immediate impact on the senses. At the same time, songs are attached to and derive from gender-specific roles and clichés, images of "masculinity" and "femininity" which are components of a complex cultural code and which at first glance seem more effective than anything else in processes of meaning construction [see Frith and McRobbie (1979), and Shepherd (1986 and 1987)]. The way adolescents express and act out the social rules of their gendered identity derives so clearly from these models that here at least we get a visible indication of the effectiveness of these processes. The specific quality of the song hardly matters compared to the image of the stars, and their appearance on stage or through the media. 
Then there are the discourses through which recipients attach their own meaning to their music. These discourses give rise to a popular aesthetic which sees the relation between musicians and their audiences as constituting a "community." This aesthetic seeks out the common element of diverse experiences and understands music as an "authentic" expression of these common experiences quite distinct from the influence of "commercial" processes (Frith 1982). These discourses have practically nothing to do with the music, depending as they do on processes of social construction on the part of the audience. To the fans of one musician all others produce "commercial junk." The fans do not realize that no music originates according to the criteria of "community," and that all musicians are in the same commercial context.

The closer the inspection, the more blurred become the outlines of individual songs. The songs seem to beckon as points of departure for determining content, significance and value. Instead, complex processes take their place. The songs seem to be the result of the arbitrary realisations of multi-layered processes of communication, arbitrary in as much as they present vertical sections comprised of commercially determined moments in these processes which gel into commercial products. As Mellencamp has observed: ". . . 'mass' culture is a process: a collection of discourses, scenes, or turns recycled from various media and contextualized within historical moments" (Mellencamp 1986: 80). Looked at in this way, the concrete materials that constitute a rock song are fragments of various networks of communication. The materials always operate in several of these networks simultaneously. And the choice of the materials seems entirely the listener's since music has become available in ever newer ways. Radios, cassettes and walkmans make music possible in any given place or situation. What may apply to contact with music in a disco by no means applies to the contemplative reception of music by a listener at home using headphones. Even less does it apply in a concert where the audience is counted in tens of thousands. In this way more and more levels and networks of communication have been superimposed on the music. The music video is but one continuation of this development.

Moretti rightly points out that such a phenomenon cannot be approached "as if it were a vector pointing neatly in one direction, but as if it were a light source radiating in several directions or a field of forces in a relatively stable equilibrium"' (Moretti 1983: 22). Of course, one could justifiably claim that this obervation is applicable to any work of art. Eco states that "every work of art ... presents itself as an object open to an infinite number of kinds of reception" (Eco 1973: 60). But can the circumstances outlined here really be subsumed under the concept of the "work of art," even in Eco's open version? Is a rock song, as Franz has put it, an "instruction for reception" with a "potential of meaning which is embedded in the total structure of the 
[artistic] text" (Franz 1984: 301) and subsequently decoded and rendered explicit in the course of social use?

In seeking an answer we can avail ourselves of the general definition of the semantics of artistic texts formulated by Franz. Franz writes that "works of art possess a dual character: they are form-engendering productions or actions, and they are specific and complex forms as carriers of significance and meaning" (Ibid: $248 \mathrm{ff}$.). As such they qualify as forms of the realisation of artistic texts. These texts are described as follows:

Artistic texts are indicatory texts. They possess a structure-engendering form through regularities which is specific in each instance as to material and meaning. Aesthetic rules of text formation are rules pertaining to the formation of structures and patterns ... . (Ibid: 236)

The basis of this ability of the rules of text formation to build structures and patterns is the ability of artistic means of expression to form "sign complexes" or a "semiotic system":

Significances capable of construction have correspondences in form; in other words: organisation of signification occurs after the organisation of form. This is the basic law of the formation of iconic signs and meta-signs. (Ibid: 230)

Franz lists the following semantic constituents of artistic texts: "evidential content, connotational content, subjective and objective intention, invariant content and the content received" (Ibid: 241). The contradictory relationships among these possible contents mediate a multi-layered complex of meaning that arises through coherence-formation: "the core, semantic process of textformation is coherence-formation, i.e., the construction of a complex of meaning whose components are inter-related in a specific manner" (Ibid: 245). Franz adds that ". . . artistic text-formation does not just involve semantic meaning formation in itself, but meaning formation in the context of the ideological meaning flowing from human action" (Ibid: 236).

At first glance it appears that these definitions could be applied to rock songs, perhaps with some qualifications. However, on closer examination it appears that such application would presuppose a number of unsupportable assumptions. The assumption that structure and pattern are governed by meaning (this connection, according to Franz, constituting the basis of text formation) applies only in a very limited way. In their dependence on characteristic musical stylistic traits, rock songs are highly conventionalised. In the absence of notation, they are reduced largely to memorizable patterns determined to a large extent by technical considerations (e.g. the storage capacity of a sequencer, the programmability of synthesizers, the capacity of amplifiers and the circuitry of musical effect devices such as wah-wah pedals 
and phasers). Furthermore, rock songs result from a production process in a studio with a division of artistic labour and assembly-line procedures which lend themselves only very rarely to control by individuals: subjective intuitions are rarely if ever objectified (Wicke 1987: $11 \mathrm{ff}$.). Structures of meaning through coherence-formation cannot develop: a) because of the actual modes of production; and b) because of the multi-functional parameters described above which turn different structural levels such as rhythm, sound, the singing voice and lyrics into functional elements in a number of different contexts. It would therefore amount to an impermissible reduction to conceptualise rock songs in terms of the "ascertainment of meaning" (Franz 1984: 197) and their semantics in terms of ideological questions relative to the meaning of life which Franz quite properly postulates as the necessary condition for the formation of artistic texts. These spiritual questions may well, and surely do, play a role as one component among many. Important among these other components is the experience of one's corporeal sensuality in the physical movements of dance (this sensual experience is not necessarily at odds with spiritual experience). But surely what dominates is the factor of the "ascertainment of identity," that is, the activation and confirmation of the recipients' subjective identity in an active rapport with the music and the surrounding networks of social interactions from communities of fans and group cultures to the mass experience of the stadium concert. All available empirical investigations confirm this (Roe 1987: 87 ff.).

Likewise, the concept of coherence-formation as a basic determinant of artistic texts can only be applied to rock songs in the most limited way. Frith has pointed out that the rules according to which such integrity occurs are established by the technical and economic conditions of the record medium:

Twentieth-century popular music means the twentieth-century popular record; not the record of something (a song?, a singer?, a performance?) which exists independently of the music industry; but a form of communication which determines what songs, singers, and performances are and can be. (Frith 1987a: 54)

Taking television as his point of departure, Raymond Williams has concluded that the cultural processes of mass communication only appear to be mediated by individual artifacts which give the impression of a coherent formation. However, these processes always take place as a "flow" which ". . . is then perhaps the defining characteristic of broadcasting, simultaneously as technology and as cultural form" (Williams 1974: 86), which is inflected by the arbitrary way in which recipients turn towards or away from it. This model reflects much more closely actual social usage than does the notion of the communicative mediation of these processes through the individual coherence of a piece - even when commercial devices such as 
"the charts" and the concept of the "hit" seem to indicate the opposite. In the actual context of consumption, commercially emphasized and isolated hits are always embedded in a boundless continuum of musical experience, be it through broadcasting, in discos, in cassette or tape programs put together by young consumers, or in concerts where the hits are often presented as part of a seamless flow.

Finally, it must be asked whether the reception of rock songs can really be defined as the "unfolding of the complex indicatory function of the text" (Franz 1984: 301). All serious commentators agree that the same music can have not only different but mutually exclusive meanings assigned by different social groups of young people and in different contexts. This makes it impossible, to quote Grossberg, "to treat rock and roll as a set of musical texts whose effects can be read off their surface ..." (Grossberg 1984: 236).

The basic definitions of the formation of artistic texts proves to be highly problematic when applied to rock music. Two conclusions are possible. One is drawn by Franz himself with regard to the concept of "entertainment" as it is often applied to the popular arts in the German-speaking world:

The opposition - often put into practice by the arts themselves through the division of labour - between the function of entertainment and the function of the ascertainment of meaning has become historical and corresponds to the historically revealed contradiction between experiencing meaning and experiencing sensuality. However, this opposition is relative. Even in forms of entertainment shaped by the bourgeois interest in exploitation and domination, the ultimate irrepressibility of meaning is taken into account by the promise of meaning as a substitute thereof. (Franz 1984: 187)

This can only mean that the problem of invoking the rules for the formation of artistic texts in order to clarify the formal characteristics, contents and effects of rock music results in a conceptualisation of this music as an art deformed by the bourgeois interest in exploitation and domination. The other possible conclusion is that we are dealing here with phenomena which originate, to be sure, both generically and historically from the context of art, and use the same or similar materials, but to which theories of art no longer apply because we are not dealing with "works of art" or "artistic texts," and hence not with art at all. The findings sketched out above point to the latter conclusion, because they reveal characteristics which cannot be reduced to bourgeois interests in commercial exploitation. To the contrary, commercial exploitation is applied to these forms of popular art because of these irreducible characteristics. I am advocating neither an uncritical legitimation of existing forms of popular art, nor a surrender of all standards. I am simply posing the question as to the concepts and theories which would adequately reproduce the actual processes that occur. It will not do to dogmatically apply theories of art to cultural reality by reference to standards themselves 
derived from an ideologically mediated appropriation of reality by art. In deciding that rock songs cannot be treated as artistic texts I am not disposing of questions concerning significance and meaning. It is legitimate neither to conclude that rock music is a-semantic and exhausts itself in pure "functionality," nor that the characteristics which are specific to its form are without any importance. All that is being concluded is that the formation of rock music does not follow the rules of the formation of artistic texts. All relevant investigations have thus far reached the same conclusion and treated the conclusion as a point of departure in searching for alternative theories [see, for example, Chambers (1980 and 1985), and Grossberg (1984)]. A number of approaches have been developed whose theoretical points of departure will now be examined.

\section{THE ROCK SONG AS CULTURE: SYMBOL, STYLE AND TEXT}

In the 1970s Paul Willis presented a "theory of the social significance of pop music" (Willis 1974) which owes a debt in its analysis of culture to the Centre for Contemporary Cultural Studies at the University of Birmingham. This approach has been formulated most accurately by Stuart Hall, John Clarke, Tony Jefferson and Brian Roberts:

The "culture" of a group or class is the peculiar and distinctive "way of life" of the group or class, the meanings, values and ideas embodied in institutions, in social relations, in systems of belief, in mores and customs, in the use of objects and material life. Culture is the distinctive shapes in which this material and social organisation of life expresses itself. A culture includes the "maps of meaning" which make things intelligible to its members. These "maps of meaning" are not simply carried around in the head: they are objectified in the patterns of social organisation and relationships ... Culture is the way the social relations of a group are structured and shaped; but it is also the way those shapes are experienced, understood and interpreted. (Hall et al. 1976: 10-11)

For Willis, this view of culture results in a need to analyze the relationship of rock music to its listeners as well as its significance as a component of the complex network constituted by the relationships of the specific cultures of certain social groups of young people. In examining their everyday habits (Lebensform), their tangible behaviour and underlying social relationships and values, Willis sought to trace that "map of meaning" which turns individual and significant artifacts into symbols and which renders their lifestyle as capable of being understood and interpreted. Willis writes:

Any one piece or type of music ... is always taken in the light of its subjective and usually non-verbal understanding of the whole complex of the pop world scene, and its surrounding attitudes, values and symbolic systems. The "use" made of any particular element in this symbolic whole depends 
on the rest of the system, and the individual's or group's self recognition of their position within this system ... What we are confronted with is a whole way of life interpenetrated by a whole symbolic system, not a series of discrete bits of behaviour alongside a series of discrete cultural artifacts. (Willis 1974: 6)

Here music is understood as a cultural object whose significance and value - as that of any other object - is fully determined socially but within objective limits set by internal musical parameters:

Some kinds of social meanings ... will be held and reflected fully within it, others partially, and still others not at all. This kind of limitation will depend crucially on internal structures ... but these internal parameters are not, as it were, always alive and fully operational. They only come alive and become capable of holding meaning when they rubbed against the real life experience of a particular group. (Ibid: 16)

Convincing though this approach is for the interpretation of the social and cultural use of music in youth cultures [Willis himself has applied it to the analysis of a motorcycle gang and a group of British hippies - see Willis (1978)], it reveals its weakness at this very point. In both cases, which Willis regards as illustrative of his analytic method, music (rock 'n' roll and hard rock for the motorcycle gang, psychedelic rock for the hippies) plays a constitutive role in the formation of the cultural coherence of each group, although its significance is not manifested until this coherence has become apparent. It is presupposed as an object with certain formal characteristics "internal parameters" - and the question as to why it has been produced with these and not other characteristics is not broached.

Dick Hebdige has elaborated on and advanced this approach (Hebdige 1979). His work is clearly influenced by the French structuralism of Claude LéviStrauss, Roland Barthes and Julia Kristeva. Basing his approach on Umberto Eco's proposition that "not only the expressly intended communicative object . . . but every object may be viewed . . . as a sign" (Eco 1973: 97), Hebdige analyses the everyday objects which are significant for the cultural behaviour of youth subcultures in order to give them recognition as signs of organised significance. Subcultures as "cultures of resistance" (Hebdige 1979: 85) revise these significances in a creative practice which Hebdige, drawing on Lévi-Strauss, calls "bricolage," that is to say, the re-arrangement and re-contextualisation of objects by the intentional demolition of their seemingly "natural" role in social use. Ordinary and everyday materials, items of clothing, leisure apparel, hairstyles and all kinds of fashionable accessories are inserted into a symbolic order of their own, in a "subcultural style" which opens them to "blocked readings" within which groups give expression to their own experiences: "the communication of a significant difference, then (and the parallel communication of a group identity), is the 
'point' behind the style of all spectacular subcultures"' (Ibid: 102). Being integrated into such a "style," cultural objects acquire their significance within the specific subculture; this in turn renders the subcultures readable as texts, and analysable as to their semantics. Hebdige has illustrated this approach using as an example British punk culture (Ibid). Understood from this perspective, music is included in the subculture as a semantic element of the subcultural text, and becomes at the same time an exemplary embodiment of its stylistic principles, which can then be conveyed through the music and developed within it. The subculture's "style" has its equivalent in the music generated within it. Subsequent appropriation and dissemination by the music industry of a subculture's "style" disrupts its local boundaries and robs it of its subversive potential, a process which in turn leads to the formation of new subcultures with their own musical styles.

It would appear that the territory left vacant by Willis in terms of explaining the production of music has now been filled by Hebdige. However, the multifaceted and ambivalent quality of Hebdige's concept of style obscures the problem rather than solving it. The concept of musical style that lies behind labels such as punk rock, Heavy Metal, and reggae cannot be equated with Hebdige's concept of style, that is, with the objective ensemble of a specific system of symbols. Hebdige's concept suggests an analogy which does not exist. Things become uncertain for Hebdige where the significance of music is concerned because he attempts to grasp it on the meta-level of style alone. Below this level the specificities of musical form become interchangeable.

Dave Laing sets out to ask more precise and specific questions concerning the significance and content of music in a critique of Hebdige's analysis of the subcultural style of British punks: "the key questions here are how did punk generate meanings, what were those meanings and which of them were consumed by listeners to the music and in what way?" (Laing 1985: ix). Laing makes use of discourse theory (Foucault 1981, and Kristeva 1975):

Too much cultural criticism, particularly from a Marxist viewpoint, has been content to privilege "social conditions" over "language systems" (and their products, such as songs or films), so that the meaning or value of a song is seen to lie on how adequately it mirrors contemporary social reality . . . The values of introducing a bridging concept such as "discourse" is that it helps avoid the danger of reducing the signifying level of songs to a mere effect of the current class struggle or social conditions. (Laing 1985: xii)

Rock songs are for Laing "cultural artifacts" (not exclusively musical ones) which are in principle analysable as texts. He uses the broadest version of the structuralists' concept of text as formulated by Roland Barthes, according to which: "text is to be understood as the production of significance and not 
as a philological object"' (Barthes 1977: 126). In their semiotic analyses (which view complexes of signs in the shape of texts) Laing sees the possibility of tracking down the meanings actually realized through the cultural use of songs. This approach:

\begin{abstract}
... thus provides a way of avoiding the difficulties encountered frequently by purely musicological or purely linguistic analyses of popular songs. For each of these tends to privilege just one aspect of a song (the musical structure of chords, harmony, melody etc., or the meaning of the lyrics) to the detriment of the rest. It is surely clear that in many instances neither of these constitutes the centre of attention for an audience. Most often in popular music, the focus is the singing voice, combined in the spotlight of live performance with the physical presence of the singer her/himself. (Laing 1985: ix)
\end{abstract}

As a consequence, Laing is able to follow up all configurations of signs that constitute significance, be they musical, gestural, visual or verbal: "meaning in popular music has various sources: sounds, words, pictures, gestures" (Ibid: 41). However, these configurations only assume importance and significance within a discourse or discursive formation defined by Laing as that "which supplies for anyone entering it a series of positions to adopt, roles to play and rules to adhere to" (Ibid: 99). Accordingly, discourses are the social mechanisms for the assigning of meaning. They are always effective as a complex "discursive system" or "discursive formation" and, by means of rules, norms and codes, as well as the socially mediated relationships which obtain among "speakers," bring about the assignment of specific meanings to specific sign objects. In themselves, the sounds, words, images and gestures which constitute rock songs have no inherent meaning. They acquire it through the way in which they are heard or seen. Since there is nothing inevitable about this, and since several discursive formations are invariably in conflict (for example, those of the dominant culture and those of subcultures), one and the same piece of music can simultaneously assume different or even opposing meanings. The dominant discursive formation "is that associated with the major record companies, the charts and music radio" (Ibid: 74), and, to be sure, it is this formation that will dominate in popular music.

Here, then, the task of music is to mobilise the different discursive formations in which it is embedded. Laing offers the most elaborate approach so far to analysing the meanings which are attached to rock music, "transmitted" by it, and derived from its practical use. However, the very thing Laing set forth to analyse slips from his grasp. His goal was to decode the songs in their specific textual spaces as carriers of significance. The detailed analysis of the discursive formations that sets songs in motion, and the analysis of meanings produced within them led Laing away from these 
very meanings because the meanings thus uncovered are attached to all sorts of cultural materials (pictures, gestures, images, the voice in its physical embodiment, styles of dress, and different fashionable accessories), but least of all in the music itself. It is no accident that in his substantial study of British punk rock, Laing devotes all of four pages to the music. This situation arises not on account of his analytical approach, but because of the nature of popular music itself, situated complexly as it is within multilayered communicational matrixes having to do with the economic and technological aspects of production. Laing has consistently asked how meanings in songs are generated rather than possessed by them. He has not related sign configurations to songs by definition, but has asked instead what is turned into a sign, for the generation of which meaning, by whom, how, and through what channel of transmission. As a consequence, Laing was able to attain a level of conceptualisation wherein the mediation of meaning through music was not confined to the sound channel of the song alone. Laing's only inconsistency lies in his handling of the concept of text. What he analyses as text is not the song as constituted through the sound channel - that is, "music" as postulated through traditional musicological concepts - but the cultural contexts produced by it. In the end Laing joins Hebdige in examining cultures rather than songs as texts, but with far greater precision as far as the role of music is concerned. Songs, their manner of performance and their specific generic characteristics are shown by him to perform the function of lending structure to the cultural contexts in which they are found. They do this by setting in motion discourses which render these connections significant and fasten meaning to them. But that means that rock songs are not capable of being subsumed under the concept of text and cannot be understood as "materially-sensually, syntactically and semantically structured, form-effective sign complexes" (Franz 1984: 295).

Evidently, it requires a different set of concepts and a different theoretical model to understand artifacts that circulate within processes of mass communication, and to reproduce them theoretically in a way that corresponds to the actual conditions of mass-mediated culture. The problem of the concept of text as it applies to rock songs and similar phenomena of mass communication is this: the concept posits a coherent whole mediated by and mediating meaning on a level where the coherent whole does not exist, but only seems to. Mass communication is characterised by interruptions, by the incidental use of culture as "background," and by instances of culture that do not communicate functionally. The formal characteristics of mass-communicated cultural artifacts only communicate effectively in fragments. Furthermore, the formal configurations imprinted on these artifacts and perceived by the senses consistently display an instability that depends greatly on context. For the dancers at a disco, the same music that they may have encountered as a song at home through headphones takes on 
a different configuration as dance music. Not only is the relationship of accompaniment to melody complelety reversed (the rhythm and bass that seem to play a subordinate role when listened to at home become in the disco primary points of orientation); the music loses its autonomy as beginning and end melt away in a "run-on" of items. It has now become quite customary to produce the same music with different mixes aimed specifically for the "club" or the "disco." Here we get glimpses of the transformations sensed by producers and used by the industry for multiple merchandising of the same piece. Presumably the perception of the musical object differs to a degree that corresponds to the communicative connections described here. Here, surely, is one of the causes for the prevalence of stereotyping and structural redundancy in these forms of music.

\section{THE ROCK SONG AS MEDIUM}

Variability in contexts of reception brought into being by audio-visual means of mass communication breaks down the internal coherence of a song and leads to shifts in the song's centre of gravity brought about by ever new connotative combinations between the music and the various contexts of reception that are now possible. Frith rightly points out that this process extends to the personal consumption of songs - that their "possessibility" is an appreciable aspect of their reception:

Because of its qualities of abstractness ... music is an individualizing form. We absorb songs into our own lives and rhythms into our own bodies; they have a looseness of reference that makes them immediately accessible. Pop songs are open to appropriation for personal use in a way that other popular cultural forms (television soap operas, for example) are not ... (Frith 1987b: 139)

This openness of songs - but not arbitrariness: the precision of the fans' selective behaviour bears this out - and the exact semantic placement of the cultural connections produced through them strongly suggests that music here has a medial rather than a textual quality. It suggests, indeed, that music is a medium, a mass medium to be precise.

This is the only way to resolve the contradiction that has defeated all analyses so far: mediation of meaning does occur in rock music although it cannot be detected in it. Like all forms of popular music rock has a mediating function rather than being singled out as an object of appropriation. An understanding of the form-specific characteristics of this function would require an aesthetics of mediation (a "medial" aesthetics) whose development has yet to be initiated. All that I can do in this paper is to identify the problems of developing such an aesthetic and indicate directions to their solution to the extent that current research permits. 
If we begin by ascribing medial rather than textual qualities to rock music (an ascription which in all probability is applicable to all other "popular arts" with some modifications), we are employing a concept of "medium" which is not confined to the usual notion of technical mediation (i.e., a purely instrumental function). We may be helped by the original meaning of the term derived from the natural sciences. A medium is an agent or a material substance in which a physical or chemical process takes place [see Williams (1983: $203 \mathrm{ff}$.)]. Just as the qualities of the medium determine the processes possible within it, the qualities of the medium of music are of decisive importance for the cultural processes realized through it. It is important to bear in mind that the specific form of music as a medium does not result from the music being an object of appropriation of the external world and external reality, but is itself an agent which mediates this process of appropriation in a culture-specific form.

Irene Dölling has pointed out that "cultural forms"' are always implicated in the behaviour through which people appropriate the world and come to terms in practical ways with the circumstances of their lives. Cultural forms are involved in the processes through which individuals internalise, organise and interpret their experiences, through which they "work out" the contradictions of their society and cope with them as individual conflicts (Dölling 1986: 15). She continues: 'it is characteristic of 'cultural forms' that they are capable of objectifying societal contradictions in a palpable fashion, in forms which derive from immediate individual experience" (Ibid: 83). Such "symbolic representations of the social dimensions of individual existence" (Ibid: 90) in everyday cultural forms have been described by Hebdige and Laing, albeit within the narrower compass of "conspicuous subcultures" and "symbolic forms of resistance." Dölling, however, views such symbolic and cultural forms as a general feature of living, that is, a mediation of processes of social and individual reproduction. An altogether essential aspect of this process is as follows: prior to the creation of a coherence of meaning in which the individual circumstances of everyday living can be experienced as meaningful, there exists a pattern of interpretation and evaluation which structures the perception of these circumstances. Whatever their differences, the shared characteristics of these patterns is this: as socially produced cultural forms in which processes of individual life occur, they mediate the nexus of the meanings of individual activities, needs and abilities in the concreteness of their social constitution. However, this can happen only if complex structural meanings are formed from the linguistic, tangible or iconic symbols in which the essential social relations of individual lives are made visible. In this way, these relations as rendered visible are knitted together as texts, "cultural texts" that is, through which individuals express their subjective identity and give "personal meaning" (Leontjev 1979: 148) to their relationship with the world. 
Materials for this process are found in everyday cultural forms, in metaphors, in symbols, and in the collective use of objects imprinted with meaning which individuals integrate into their own existence in such a way that coherent meaning is created as a means of confirming their own identity and of pinning down a "personal meaning" in their relationship to the world. It is not difficult to discover symbols that foster meaning and consequently a sense of identity in the domestic setting, or manners of speech in the iconic elements that suffuse everyday speech.

This process is of particular importance for young people. Adolescence constitutes a time when the search for identity is paramount and when an inherent lack of stability creates a special need for objectified confirmation in the process of becoming a subject and forming personality. Among young people "cultural texts" are especially conspicuous and rich: bizarre apparel loaded with trendy accessories - pins, rings, chains - rooms crammed with pictures, posters, placards and souvenirs. And then there is the ritual use of leisure objects: motorcycles pampered as symbols of virility. How such texts originate has so far only been investigated with respect to "conspicuous subcultures." However, we can speculate that there is nothing arbitrary about these texts. The meanings of these objects, pictures and metaphors that accumulate in the history of their use must be apprehended, must be experienced as subjectively significant, their juxtaposition must generate significance. The decisive mediation of all this takes place through music. Its importance increases to the extent that the "cultural texts" which foster meaning and identity cannot, prior to the fact of music, be the repository of lived experience. Here lies the reason for the powerful efficacy of music in the formation of individual world senses and senses of identity (Weltanschauung). No matter how banal, slight, grotesque, stereotyped and standardised the music might be, its form-specific characteristics make this process possible through their medial function.

In order to understand this process adequately, we must abandon notions taken from the concept of the work of art where the single song would be the point of reference. Here, an analogy suggests itself in the form of the single frame of a film. This frame is indispensable as a concrete and selfcontained image. Yet, it disappears completely, losing its independence in the sequence of images that conveys motion. The same way of thinking may be applied to rock songs, except that here the specific shape of each in the form of structured acoustical and verbal material is absorbed into a "cultural shape" just as the single frame is absorbed into a dynamic shape. This characteristic of popular music has long been recognised and used by the broadcast industry for the targeting of audiences for commercial purposes. Market research has become accurate to the point where audiences can be targeted successfully according to age, gender, social status, occupation, leisure and consumer habits through playlists averaging about 50 songs. This 
procedure is based on the cultural shapes into which single songs are coalesced as they are being listened to. By the same token, tailor-made commercials are broadcast to those targeted audiences and delivered by means of these same cultural shapes. An entire industry (programming, marketing and consulting) has sprung up, dedicated to devising accurately targeted music programs.

These cultural shapes, originating as the result of the consumption of single songs, are mediated and constitute a specific matrix of activities. The matrices form a kind of code which structures cultural behaviour, which is formed in the course of the songs' reception, and which is attached to their respective shapes. The code includes strategies of reception and of communication determined by the peculiarities of the cultural shapes. These strategies create orders of precedence among the several networks of communication in which the constitutent materials of a song circulate in each case. For instance, in the case of Heavy Metal live experience in informal groups dominates among possible contexts of reception because of Heavy Metal's specificity as a musical genre. In contrast, reception through headphones dominates in the case of the singer-songwriter ballad. In the case of the singer-songwriter ballad, the specific communicative context laid down by the ballad's music and lyrics is crucial, while with a Heavy Metal song these components are relativised to the point of interchangeability in order to give pride of place to the gestural and visual aspects of presentation. Appropriate modes of cultural behaviour belong to both genres. To mention the most obvious: regular attendance at club events with live music for the Heavy Metal fan; the collecting of records, lyrics, interviews and so on for the fan of singer-songwriter ballads.

In the course of such activities the referential elements contained in the musical, verbal, visual and gestural material of the songs are filtered out and combined into a pattern of signification. This pattern of signification is both general and stereotypic, and because it develops in a pointilistic and incidental manner that is always dependent upon the context of reception it makes for a high degree of standardisation in the shape of the song. Thus, there is no question of accumulating a great variety of referential elements mediated by the songs, or of identifying and exploring their individual characteristics. To the contrary, there is a process of tracing a pattern that is confirmed again and again. For instance, in the case of Heavy Metal songs, this pattern of signification corresponds to a stereotype of masculinity characterised by strength, virility, communal spirit and athleticism of a particular kind. This stereotype is attached to the shape of the songs by means of the referential elements immanent in rock music: characteristic guitar sounds, the physical presence of the male singing voice, unison singing, the repetition of fragments of lyrics and suggestive gestures; and through ritualised forms of presentation: stereotypic movements on stage, the 
manner of holding and playing the guitar, its suggestive use as a phallic symbol, and so on. In every Heavy Metal song all this manifests itself and so constitutes and confirms this pattern of meanings.

In a similar manner, early British beat music fashioned the stereotype of youth. Examples are to be found in the songs of the Beatles, the Rolling Stones and the Kinks until about 1966. American rock music of the latter half of the 1960s (as exemplified by Janis Joplin, Bob Dylan, the Grateful Dead and so on) is based, on the other hand, on the stereotype of freedom. As differentiation increased in the development of rock music, the patterns of signification at the centre of these songs and their various stylistic characteristics came to differ, too. The patterns towards which individual songs converge are easily identified in tracing the referential elements attached to and accumulated through the material used in all manner of massmediated culture. These referential elements may have been formed within the history of popular music itself: in reference to the rich symbolism of the amplified guitar, to popular films, the verbal and pictorial stereotypes of comics, or the iconography of advertising; in short, to the whole reservoir of the signs and symbols of everyday cultural forms as described by Dölling. These resources are constantly recycled and appear in songs in fragments only, sometimes completely isolated from the shape of the song but sufficiently present to connect it to a certain pattern of significance or, indeed, to create a new one.

References such as the image of the musician or the band which are embedded in the material of the song and its appropriate discursive context are then identified within various networks of communication regardless of the form-specific context in which they occur. Such references are contained mostly in the physical presence of the singing voice (rooted in the history of popular music or in the sound-sight stereotypes of films); in configurations of sound which have acquired significance in music's cultural usage or in extra-musical contexts such as the environment or the workplace; in images of motion formed by the manner in which a song is presented; through the associations the stylistic organisation of songs have with the popular world of images (in comics, films or advertising: for example, the "strutting" of rock guitarists); or through suggestive key words or slogans in the lyrics. No coherent form within the individual shapes of songs can be detected, and none should be sought, because coherence-formation does not occur until individual songs are fused through actual use into cultural shapes. Hence, the often glaring banality of the songs means little; no stable formal characteristics and no specific modes of reception (concentrated, partial or incidental) are required. The referential relationships which songs internalise are momentary, of varying density, and can be taken on board in completely incidental situations. Because of their specific manner of production, that is, because they are mediated through music, these patterns of meaning serve to 
structure cultural behaviour - they structure "affect." The work of Lawrence Grossberg has moved in directions similar to this line of thought, except that he uses the term "rock ' $n$ ' roll apparatus" rather than "cultural shape." In addressing this problem of cultural behaviour or "affect," Grossberg has argued as follows:

The notion of "affect" points to the fact that there is more to the organization of our everyday lives than just a distribution of meaning, money and power. There is a variable distribution of concern and energy: some things "feel" different than others, some matter more, or in different ways, than others. "Affect" refers to that dimension or plane of our lives that we experience as moods, feelings, desires and enervation. It is related to meanings but is not reducible to them, for an event, even with a specifiable meaning, will have radically different effects depending upon its relations to our affective life, depending on its place in our "mattering maps." (Grossberg 1985: 20)

The patterns of significance formed by songs at the level of cultural shapes are invariably integrated into an affective structure of meanings. This structure regulates the emotional energy invested in specific activities. During adolescence, when this level plays an especially important role, emotional energy is expressed very directly. Experiences and activities are either "boring" or "not-boring," or, to use the appropriate jargon, "straight" or "hip." Behind this expression there surely lies an affective structure of meaning which is oriented towards content through the signifying stereotypes of music. The signifying stereotype of "youth," for instance, as produced in the early songs of the Beatles, the Who and the Rolling Stones, results in an affective strategy of classification oriented towards a content different to that of "virility." Cultural behaviour in these two cases is structured in significantly different ways. In the former it is directed at everything that implies a clear line of demarcation from adulthood as well as from childhood, that is to say, the discovery, appropriation and occupation of socio-cultural areas of one's own, the development of cultural modes of behaviour suitable for emphasizing "independence" from parents (hence the cult of the portable radio and the scooter), and the development of ritualised partnerships. In the latter case the centre of gravity moves towards behaviour traditionally thought of as virile (sports, especially soccer, drinking, going to bars, and the display of virility in dress and manners). In this way, the cultural shape which music assumes in actual use comprises strategies of reception, perception and communication, signifying stereotypes and affective patterns of meaning. The cultural use of music is determined through socially structured but individual living conditions and the way of life that flows from them. As a consequence, cultural shapes are as socially differentiated as are the content-specific characteristics of the music. It has often been overlooked that the signifying stereotype of "youth," for example, can mean altogether 
different things to youth groups situated differently in society. This explains how the same songs can be integrated into different cultural shapes, or put together to form entirely new ones through a shift in their social context. The reception of American rock ' $n$ ' roll by British working-class youth during the 1950s provides a classic example, as does the reception of transnational rock music in the German Democratic Republic.

Integrated into the forms of cultural shapes, music performs an essential service: it acts as a medium for the translation of social experience into "personal meaning." The rules of transition are supplied by signifying stereotypes and the affective strategies of classification through the cultural modes of behaviour that they set in motion. According to these rules of transition, the objective, linguistic and iconic symbols present in the symbolic and cultural forms of everyday experience are connected to form a context in which meaning and identity are generated. This context becomes available as a socially constructed individual means of reflection. By means of it, different moments of everyday experience are fitted into an order that has meaning for the individual. A definite way of looking at the world is objectified. This meaning is neither mirrored nor portrayed in the songs, and is, as a consequence, not detectable in them. Rather, it is produced by means of them. Songs constitute a medium which equips individuals to experience and reflect on their living conditions in a particular way. Here, music is so very effective because it is socially produced, yet individually and subjectively realised. The key to understanding this effectiveness is the realisation that the process of the social and cultural construction of a personal identity is achieved through music as that music is situated in its cultural shape. The analysis of this process remains a challenge - a challenge that it is more urgent than ever to meet.

(translated by Regina Datta. Ernst Oppenheimer and Peter Wicke)

\section{REFERENCES}

BARTHES, ROLAND.

1977: Image-Music-Text. New York: Hill and Wang.

CHAMBERS, IAIN.

1980: "Rethinking Popular Culture," Screen Education, 36: 113-117.

1985: Urban Rhythms: Pop Music and Popular Culture. London: Macmillan.

DÖLLING, IRENE.

1986: Individuum und Kultur. Berlin: Dietz. 
EGO, UMBERTO.

1973: Das offene Kunstwerk. Frankfurt/Main: Suhrkamp.

FOUCAULT, MICHEL.

1981: "The Order of Discourse," in Untying the Text, Richard Young, ed. London: Cape.

FRANZ, MICHAEL.

1984: "Wahrheit in der Kunst," in Neue Überlegungen zu einem alten Thema. Berlin: Aufbau.

FRITH, SIMON.

1982: "The Sociology of Rock: Notes from Britain," in Popular Music Perspectives, I, David Horn and Philip Tagg, eds. Exeter: International Association for the Study of Popular Music.

1987a: "The Industrialisation of Popular Music," in Popular Music and Communication, James Lull, ed. Beverly Hills: Sage.

1987b: "Towards an Aesthetic of Popular Music," in Music and Society: The Politics of Composition, Performance and Reception, Richard Leppert and Susan McClary, eds. Cambridge: Cambridge University Press.

FRITH, SIMON and ANGELA MCROBBIE.

1979: "Rock and Sexuality," Screen Education, 29: 3-19.

GROSSBERG, LAWRENCE.

1984: "Another Boring Day in Paradise: Rock and Roll and the Empowerment of Everyday Life," Popular Music, 4: 225-258.

1985: "Rock and Roll in Search of an Audience or Taking Fun Too Seriously," Unpublished Manuscript.

HALL, STUART, ET $A L$.

1976: Resistance through Rituals. London: Hutchinson.

HEBDIGE, DICK.

1979: Subculture: The Meaning of Style. London: Methuen.

HIRSCH, PAUL.

1971: "Sociological Approaches to the Pop Phenomenon," in Mass Communications and Youth: Some Current Perspectives, F. Gerald Kline and Peter Clarke, eds. Beverly Hills: Sage.

KEY, WILSON BRYAN.

1976: Media Sexploitation. Englewood Cliffs: Prentice-Hall.

KRISTEVA, JULIA.

1975: "The Subject in Signifying Practice," Semiotexte, 1/3: 19-26. 
LAING, DAVE.

1985: One Chord Wonders: Power and Meaning in Punk Rock. Milton Keynes: Open University Press.

\section{LEONTJEV, ALEXEJ.}

1979: "Tätigkeit-Bewusstsein-Persönlichkeit," in Beiträge zur Psychologie, W. Forst, W. Kessel, A. Kossakovski and J. Lompscher, eds. Berlin: Volk und Wissen.

MELLENCAMP, PATRICIA.

1986: "Situation Comedy, Feminism and Freud: Discourses of Gracie and Lucie", in Studies in Entertainment: Critical Approaches to Mass Culture. Bloomington: University of Indiana Press.

MELLERS, WILFRID.

1973: Twilight of the Gods. London: Faber.

MORETTI, FRANCO.

1983: Signs Taken for Wonders. London: Verso.

ROE, KEITH.

1987: "Schooling Ourselves to Heavy Metal," in Oungdom mob år 2000: Et Nordiskt och Europeiskt Perspextw, Ole Stofserg and Inga Frønes, eds. Oslo: Gylendal.

SHEPHERD, JOHN.

1986: "Music Consumption and Cultural Self-Identities: Some Theoretical and Methodological Reflections," Media, Culture and Society, 8: 305-330.

1987: "Music and Male Hegemony," in Music and Society: The Politics of Composition, Performance and Reception, Richard Leppert and Susan McClary, eds. Cambridge: Cambridge University Press.

WICKE, PETER.

1987: Rockmusik: Zur Ästhetik und Soziologie eines Massenmediums. Leipzig: Reclam.

WILLIAMS, RAYMOND.

1974: Television, Technology and Cultural Form. New York: Schocken.

1983: Keywords: A Vocabulary of Culture and Society. Oxford: Oxford University Press.

\section{WILLIS, PAUL.}

1974: "Symbolism and Practice: The Social Meaning of Pop Music," Stencilled Occasional Paper, The Centre for Contemporary Cultural Studies, University of Birmingham.

1978: Profane Culture. London: Routledge and Kegan Paul. 